\title{
Biosynthesis of Fe nanoparticles using Alhagi sparsifolia extract for the treatment of colorectal carcinoma in the in vitro condition: A pre-clinical trial study
}

\section{Type}

Research paper

\section{Keywords}

Green synthesis, Antioxidant, Cytotoxicity, Anti-human gastric cancer, Iron nanoparticles, Chemotherapeutic drug

\begin{abstract}
Introduction

The preparation and formulation of new chemotherapeutic supplements and drugs with remarkable effects for the treatment of cancer are in the priority of both developing and developed countries. Recently, iron nanoparticles have been used as modern chemotherapeutic drugs for the treatment of several cancers such as leukemia, lung cancer, breast cancer, prostate cancer, etc. In the present study, iron nanoparticles were green-synthesized using the aqueous extract of Alhagi sparsifolia leaf aqueous extract.
\end{abstract}

Material and methods

The synthesized FeNPs were characterized by analytical techniques including SEM, TEM, UV-Vis., and FT-IR. The anti-human colorectal carcinoma activity of FeNPs was evaluated using MTT assay. In the cellular and molecular part of the recent study, the treated cells with FeNPs were assessed by MTT assay for $48 \mathrm{~h}$ about the cytotoxicity and anti-human colorectal carcinoma properties on normal (HUVEC) and colorectal carcinoma cell lines i.e. HT-29, HCT 116, HCT-8, and Ramos.2G6.4C10.

\section{Results}

The nanoparticles were formed in a spherical shape in the average size of $47.24 \mathrm{~nm}$. In the antioxidant test, the IC50 of FeNPs and BHT against DPPH free radicals were 161 and $134 \mu \mathrm{g} / \mathrm{mL}$, respectively. The viability of malignant colorectal cell line reduced dose-dependently in the presence of FeNPs. The IC50 of FeNPs were 250, 293, 276, and $344 \mu \mathrm{g} / \mathrm{mL}$ against HT-29, HCT 116, HCT-8, and Ramos.2G6.4C10 cell lines, respectively.

\section{Conclusions}

After clinical study, iron nanoparticles containing Alhagi sparsifolia leaf aqueous extract may be used to formulate a new chemotherapeutic drug or supplement to treat the several types of human colorectal carcinoma. 


\section{Biosynthesis of Fe nanoparticles using Alhagi sparsifolia extract for the treatment of colorectal carcinoma in the in vitro condition: A pre-clinical trial study}

\section{Abstract}

Every year, many people die due to cancer in all of the world. So, the preparation and formulation of new chemotherapeutic supplements and drugs with remarkable effects for the treatment of cancer are in the priority of both developing and developed countries. Recently, iron nanoparticles have been used as modern chemotherapeutic drugs for the treatment of several cancers such as leukemia, lung cancer, breast cancer, prostate cancer, etc. In the present study, iron nanoparticles were green-synthesized using the aqueous extract of Alhagi sparsifolia leaf aqueous extract. The synthesized FeNPs were characterized by analytical techniques including SEM, TEM, UV-Vis., and FT-IR. The nanoparticles were formed in a spherical shape in the average size of 47.24 $\mathrm{nm}$. In the antioxidant test, the IC50 of FeNPs and BHT against DPPH free radicals were 161 and $134 \mu \mathrm{g} / \mathrm{mL}$, respectively. The anti-human colorectal carcinoma activity of FeNPs was evaluated using MTT assay. In the cellular and molecular part of the recent study, the treated cells with FeNPs were assessed by MTT assay for 48h about the cytotoxicity and anti-human colorectal carcinoma properties on normal (HUVEC) and colorectal carcinoma cell lines i.e. HT-29, HCT 116, HCT-8, and Ramos.2G6.4C10. The viability of malignant colorectal cell line reduced dose-dependently in the presence of FeNPs. The IC50 of FeNPs were 250, 293, 276, and 344 $\mu \mathrm{g} / \mathrm{mL}$ against HT-29, HCT 116, HCT-8, and Ramos.2G6.4C10 cell lines, respectively. After clinical study, iron nanoparticles containing Alhagi sparsifolia leaf aqueous extract may be used to formulate a new chemotherapeutic drug or supplement to treat the several types of human colorectal carcinoma.

Keywords: Iron nanoparticles; Green synthesis; Chemotherapeutic drug; Anti-human colorectal carcinoma; Antioxidant; Cytotoxicity. 


\section{Introduction}

Alhagi is a genus of Old-World plants in the family Fabaceae. They are commonly called camelthorns or manna trees. There are three to five species. Alhagi species have proportionally the deepest root system of any plants - a $1 \mathrm{~m}$ high shrub may have a main root more than $15 \mathrm{~m}$ long; due to their deep root system Alhagi species are drought-avoiding plants that utilize ground water, adapting in that way perfectly to the hyper-arid environment [1-4]. Alhagi species are used as food plants by the larvae of some Lepidoptera species including Coleophora argyrella which feeds exclusively on A. sparsifolia. The genus name comes from the Arabic word for pilgrim [2,5]. Alhagi in Persian is "KhareShotor" which means thistle of camels, as camels can eat it with its thorns. As such, it was figured out that the plant can retain the abdominal organs in severe thirst. In the Middle East, its boiled or distillated juice is used against kidney and bladder stones. Also, the plant foliage is the habitat of a special insect which produces Manna of hedysarum or Tarangabeen, which is a honey remedy for neonatal jaundice [5-9]. The genus is known as an important medicinal genus in folk medicine around the world. The whole plant of Alhagi genus is used as is laxative, diuretic, and expectorant [3]. The genus is effective to reduce gastric acidity [4]. The Alhagi genus showed diaphoretic, antiseptic, healing of wounds properties [5]. The essential oil of the leaves of Alhagi genus is used to treat rheumatism [6]. Alhagi genus is rich in phenolic compounds, glycosides, sterols, steroids, resins, alkaloids, flavonoids, fatty acids Coumarins and vitamins. The presence of these different classes of secondary metabolites in Alhagi genus is the chiefly responsible for its bioactivity $[4,7-9]$.

Nanotechnology, also shortened to nanotech, is the use of matter on an atomic, molecular, and supramolecular scale for industrial purposes. The earliest, widespread description of nanotechnology referred to the particular technological goal of precisely manipulating atoms and molecules for fabrication of macroscale products, also now referred to as molecular nanotechnology [10-12]. A more generalized description of nanotechnology was subsequently established by the National Nanotechnology Initiative, which defined nanotechnology as the manipulation of matter with at least one dimension sized from 1 to 100 nanometers. This definition reflects the fact that quantum mechanical effects are important at this quantum-realm scale, and so the definition shifted from a particular technological goal to a research category inclusive of all types of research and technologies that deal with the special properties of matter which occur below the given size threshold. It is therefore common to see the plural form "nanotechnologies" as well as "nanoscale technologies" to refer to the broad range of research and applications whose common trait is size. Scientists currently debate the future implications of nanotechnology. Nanotechnology may be able to create many new materials and devices with a vast range of applications, such as in nanomedicine, nanoelectronics, biomaterials energy production, and consumer products. On the other hand, nanotechnology raises many of the same issues as any new technology, including concerns about the toxicity and environmental impact of nanomaterials, and their potential effects on global economics, as well as speculation 
about various doomsday scenarios. These concerns have led to a debate among advocacy groups and governments on whether special regulation of nanotechnology is warranted [9-13].

Nanoparticles are widely used because of their high surface-to-volume ratio, small size, and excellent reactivity. The effects of nanoparticles should be predictable, controllable and get the desired results with minimal toxicity. Metallic nanoparticles used in treatment and diagnosis, in addition to being non-toxic, must be biocompatible and stable in vivo. Also, by making appropriate changes in the surface of metallic nanoparticles, they will have a wide range of applications by binding to biomolecules and various carriers to cross the cell membrane and target the desired part in the body. One of the important points in the production of nanoparticles is the use of cost-effective and efficient precursors [12-15]. There are three biological, chemical, and physical methods to synthesize the nanoparticles. Chemical and physical methods are time-consuming and costly. In addition, these methods use some toxic additive chemicals that cause adverse effects on medical applications by adsorption on the surface. Applying the principles of green chemistry has decreased the use of toxic compounds or hazardous solvents, provided optimal regeneration conditions and ameliorated materials for the chemical processes, and raised new sources for green synthesis [12-14]. Therefore, one of the primary goals of green nanotechnology is to produce nanomaterials without harm to human health or environment, and to develop and design nanomaterials and products that are suitable solutions to environmental problems. The synthesis of nanoparticles by similar biological methods results in greater catalytic activity and limits the use of toxic and expensive chemicals [1013]. In biological methods, plant extracts, enzymes or proteins carrying natural resources are used to produce or stabilize nanoparticles. The nature of the materials used to make nanoparticles influences the shape, structure and morphology of these nanoparticles [10-14]. Biological systems involved in the green synthesis of nanoparticles, plants and their derivatives, as well as microorganisms such as algae, fungi, and bacteria. Plant parts such as roots, leaves, stems, fruits, and tiny parts such as the kernel and skin of the fruit are suitable to synthesize the nanoparticles because their extracts are rich in phytochemicals that act as stabilizing and reducing substances [1013]. The use of natural plant extracts is a cheap and environmentally friendly process and does not require intermediate groups. Short time, no need for expensive equipment, precursors, high purity product and excellent quality without impurities are the features of this method [14,15].

Recently, scientists have used the anticancer effects of medicinal plants in several traditional medicines for synthesizing the iron nanoparticles containing natural compounds. So far, the anticancer effects of Barleria prionitis, Lubinus perennis, Maytenus boaria, Cephaelis acuminate, Tinospora cordifolia, Sophora subprostrata, Euphoria hirta, Boswellia serrate, Lavendula officinalis, Phyllanthus niruri, Solanum seaforthianum, and Cephalotaxus harringtonia drupacea have been proved [15]. In the current research, the properties of iron nanoparticles formulated by Alhagi sparsifolia leaf aqueous extract against common colorectal carcinoma cell lines i.e. HT-29, HCT 116, HCT-8, and Ramos.2G6.4C10 were evaluated. 


\section{Material and Methods}

\subsection{Preparation and extraction of aqueous extract}

First, the dried leaves of Alhagi sparsifolia were grounded. Then, $80 \mathrm{~g}$ of the sample was macerated in $500 \mathrm{~mL}$ of boiling water for $3 \mathrm{~h}$. Next, the filtration and evaporation were applied to obtain the concerted extract. Finally, the extract was put in a freeze drier for $72 \mathrm{~h}$ to produce the powder extract of Alhagi sparsifolia.

\subsection{Green synthesis and chemical characterization of FeNPs}

A reported procedure (with some modifications) was used to green-synthesis of FeNPs [16]. First, $10 \mathrm{~mL}$ of the plant extract $\left(0.2 \mathrm{~g}\right.$ in $100 \mathrm{~mL}$ of water) was added to $30 \mathrm{~mL}$ of $0.02 \mathrm{M} \mathrm{FeCl}_{3} \cdot 6 \mathrm{H}_{2} \mathrm{O}$. Then, the mixture was stirred for $90 \mathrm{~min}$ at $50^{\circ} \mathrm{C}$. After the time, the iron nanoparticle was formed. The color-changing from yellow to black indicated the formation of iron nanoparticles. The obtained FeNPs was washed three times with water and centrifuged at $10000 \mathrm{rpm}$ for $15 \mathrm{~min}$. Finally, the precipitate was dried at room temperature. The synthesized nanoparticles as a black powder were kept in a vial for chemical characterization and biological activity evaluation.

\subsection{Antioxidant activities of FeNPS}

The free radical scavenging test was first performed by Blois in 1958, and after some modification by numerous studies in its current form. DPPH method is one of the most widely used methods for estimating antioxidant content. DPPH is a stable radical that reacts with hydrogen atom compounds. This test is based on the inhibition of DPPH, which causes the decolorization of DPPH solution by adding radical species or antioxidants. DPPH changes color from purple to yellow by taking an electron from the antioxidant compound. The free radicals in DPPH are adsorbed at $517 \mathrm{~nm}$, which follows Beer Lambert's law, and decreased absorption is linearly related to the number of antioxidants; the higher the number of antioxidants, the more DPPH is consumed and the more purple turns yellow [15].

This experiment was performed with few changes in the method of Lu et al [24]. $0.5 \mathrm{ml}$ of $0.1 \mathrm{mM}$ DPPH solution prepared in $95 \%$ ethanol was mixed with $100 \mu \mathrm{l}$ of FeNPs. The resulting solution was kept in the dark at $38^{\circ} \mathrm{C}$ for 31 minutes. The absorbance of the samples was then read at $518 \mathrm{~nm}$. To compare the activity of FeNPs, standard BHT compound was used as a standard antioxidant [15].

To determine the amount of IC50 (IC50 is defined as the concentration required to inhibit 50\% of the antioxidant activity) for FeNPs, experiments were performed at eleven different concentrations of the desired nanoparticle solution and BHT. Each experiment was performed in three shifts and the mean values were calculated. Percentage of radicalization activity was calculated through the following equation [15]: 


$$
\text { Inhibition }(\%)=\frac{\text { Sample A. }}{\text { Control A. }} x 100
$$

In this regard, the blank adsorption indicates the adsorption of the control solution, which contains $0.5 \mathrm{ml}$ of DMPH solution and $100 \mu$ of $95 \%$ ethanol instead of FeNPs solution and adsorption of the reaction indicates the adsorption of the solution content of the FeNPs sample [15].

\subsection{Anti-human colorectal carcinoma potentials of FeNPs}

One of the cytotoxicity test methods to measure the rate of cell death is the MTT method, which is based on the formation of formazan dye by reducing the substance MTT (dimethyl thiazole 2 and 5 diphenyltetrazolium bromide) or other tetrazolium salts [24]. By breaking the MTT tetrazolium ring by mitochondrial enzymes in living cells, insoluble purple formazan crystals are formed. The formation of these crystals indicates the activity of respiratory chain enzymes and is a measure of cell viability. By measuring the amount of absorption by spectrophotometer at specific wavelengths, the number of living cells can be determined. The basis of MTT method is based on the intensity of dye produced by the mitochondrial activity of cells, that measured at a wavelength of 540 to $630 \mathrm{~nm}$ and directly proportional to the number of living cells, the increase or decrease in the number of living cells is linearly related to the activity of cell mitochondria [17]. Dead cells, on the other hand, are unable to perform this conversion due to the inactivity of their mitochondria and therefore do not show a signal. In this method, dye formation is used as a marker for the presence of living cells. In recent years, MTT testing has been the most important measurement method to evaluate the toxicity and anti-cancer effects of metal nanoparticles [17].

In this study, common human colorectal carcinoma cell lines i.e., HT-29, HCT 116, HCT-8, and Ramos.2G6.4C10 were used to evaluate the anticancer effect of FeNPs on cell culture. For this purpose, each cell line was placed separately in T25 flasks with a complete culture medium (including DMEM (Dulbecco's Modified Eagle Medium, $10 \%$ complementary bovine fetal serum, and $1 \%$ penicillin-streptomycin solution) and at $37^{\circ} \mathrm{C}$ in the incubator, cell culture was incubated with $5 \% \mathrm{CO}_{2}$.

After obtaining $80 \%$ cell density, the sample was exposed to $1 \%$ trypsin-EDTA solution and after 3 minutes of incubation at $37^{\circ} \mathrm{C}$ in a cell culture incubator with $5 \% \mathrm{CO}_{2}$ and observation of cells removed from the bottom of the plate, the sample was centrifuged at $5000 \mathrm{rpm}$ for 5 minutes and then the cell precipitate was decrypted by adding trypsin culture medium. Then, the cell suspensions after adding trypan blue dye were counted by neobar slide, and cytotoxicity test was performed by MTT method. For this purpose, in each well of 98 cell culture plates, $10 \mu$ L HT-29, HCT 116, HCT-8, and Ramos.2G6.4C10 cells were introduced with $200 \mu \mathrm{L}$ from the complete cell culture medium, and to achieve the cell monolayer density, the plate was re-exposed to $5 \% \mathrm{CO}_{2}$ at $37^{\circ} \mathrm{C}$. After reaching $80 \%$ cell growth, the culture medium was removed and the cell surface was first washed with PBS buffer, again, in all wells, a complete two-concentration culture medium of $100 \mu \mathrm{l}$ was introduced and $100 \mu \mathrm{l}$ of 
a solution of FeNPs dissolved in PBS (mg/mL2) was introduced into well No. 1. After mixing the nanoparticles in the culture medium, $100 \mu \mathrm{l}$ of it was removed and added to the second well. In the next step, $100 \mu 1$ of the second well was removed after stirring the medium and added to well 3. This operation was performed up to well 11 and thus the number of nanoparticles in each well was halved, respectively. Well No. 12 contained only one cell and complete culture medium of one concentration and remained as a control. The plate was again exposed to $5 \% \mathrm{CO}_{2}$ at $37^{\circ} \mathrm{C}$ for 24 hours and after 24 hours the cytotoxicity was determined using tetrazolium dye. $10 \mu \mathrm{l}$ of tetrazolium dye $(5 \mathrm{mg} / \mathrm{ml})$ was added to all wells, including the control, and the plate was exposed to $5 \% \mathrm{CO}_{2}$ at $37^{\circ} \mathrm{C}$ for 2 hours. The dye was then removed from the wells and $100 \mu$ of DMSO (Dimethyl sulfoxide) was added to the wells, the plate was wrapped in aluminum foil and shaken thoroughly in a shaker for 20 minutes. Finally, cell survival was recorded in ELISA reader at $540 \mathrm{~nm}$ [17]:

$$
\text { Cell viability }(\%)=\frac{\text { Sample A. }}{\text { Control A. }} \times 100
$$

Then, based on the absorption rate of each well and its comparison with the control, the inhibitory concentration of $50 \%$ (IC50) was obtained [17].

After collecting data, Minitab statistical software was used for statistical analysis. Evaluation of antioxidant results in a completely randomized design and comparison of means was Duncan post-hoc test with a maximum error of 5\%. To measure the percentage of cell survival in factorial experiments with the original design of completely randomized blocks and compare the means, Duncan post-hoc test with a maximum error of 5\% was used. The 50\% cytotoxicity (IC50) and 50\% free radical scavenging (IC50) were estimated with ED50 plus software (INER, V: 1.0). Measurements were reported as mean \pm standard deviation.

\section{Results and Discussion}

\subsection{Chemical characterization of FeNPS}

UV-Vis. analysis: UV-Vis is based on the irradiation of ultraviolet and visible photons on the sample and measures the rate of passage or absorption of matter at different wavelengths in the range of 200 to $1100 \mathrm{~nm}$. It is possible to measure the spectrum for samples in solution, solid as well as thin layers. The size of solid samples should be larger than $20 \mathrm{~mm}$. This test is not possible for powder samples. One of the important applications of UV device is to determine the concentration of the unknown solution. By having the original sample and its solvent and making several solutions with different percentages and drawing a calibration diagram based on the calculation of the maximum land, the concentration of the unknown solutions can be calculated [18,19].

The UV-Vis. spectra of the green-synthetic nanoparticles of FeNPs is presented in figure 1. The surface plasmon resonance (SPR) of FeNPs was completed using UV-Vis. spectroscopy. The produce of the biosynthetic FeNPs was observed. The advanced SPR bands at the wavelengths of 235 and $325 \mathrm{~nm}$ approved the formation of the 

$[18,19]$.

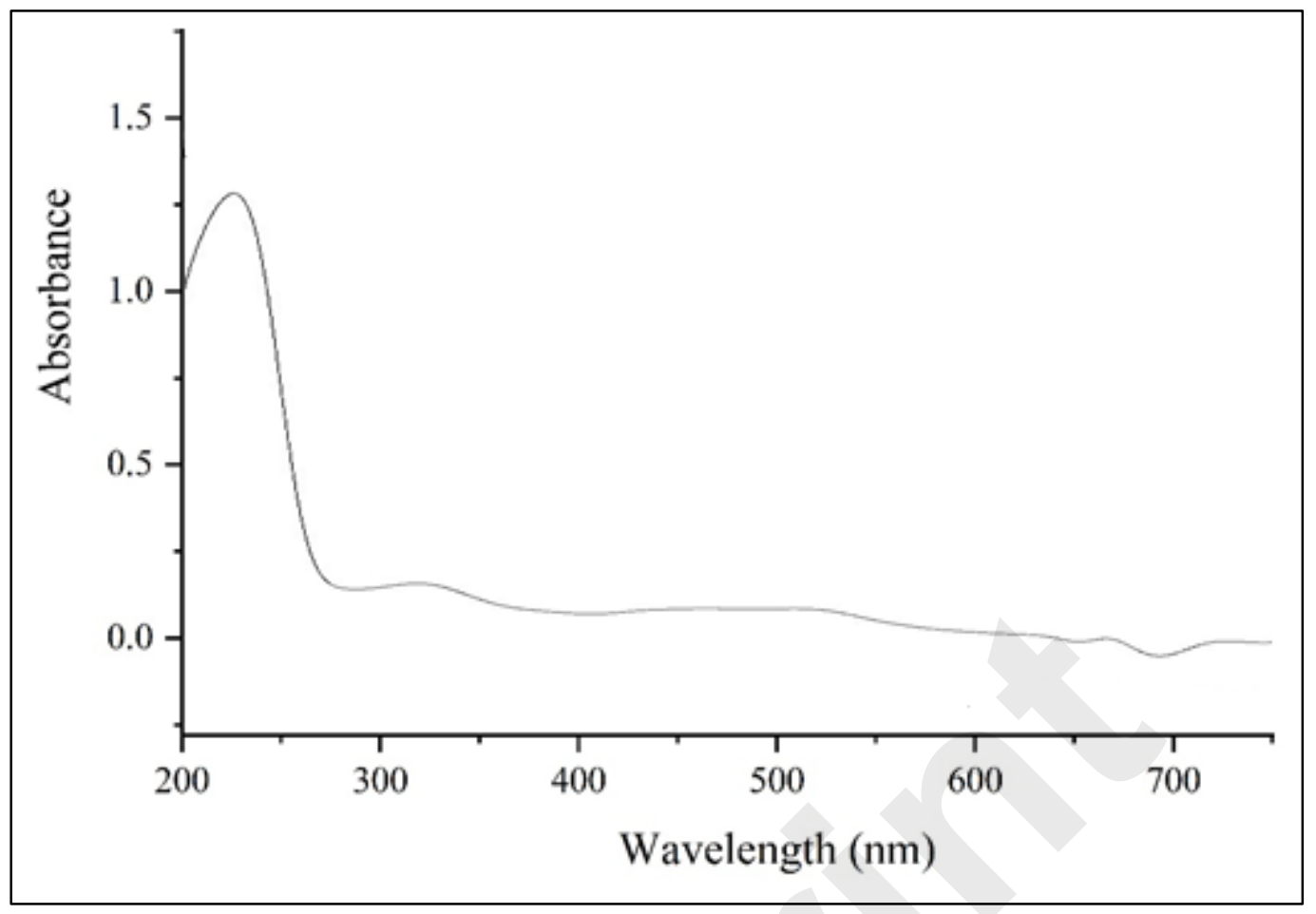

Figure 1: UV-Vis. the spectrum of biosynthesized FeNPs

FT-IR analysis: FT-IR (Fourier Transform Infrared) has been a suitable technique for analyzing materials in the laboratory. An infrared spectrum represents the fingerprint of the sample under test with absorption peaks, which depends on our vibrational frequencies between the atomic bonds of that material. Since each substance has its own atomic bonds, no two compounds with the same infrared spectrum are alike. Hence, infrared spectroscopy can be effective in better identification (qualitative analysis) of different types of materials. Also, the peak sizes are in the range indicating the amount of material present. Advanced software algorithms make this spectroscopy a great tool for quantitative analysis [20-22].

The FT-IR spectrum of iron nanoparticles is shown in Figure 2. Several peaks in the spectrum are attributed to the functional groups of different organic compounds in Alhagi sparsifolia extract, which are linked to the surface of FeNPs. The presence of secondary metabolites such as phenolic, flavonoid, triterpenes in Alhagi sparsifolia extract has been reported previously [7-9]. The peaks in 3421 and $2932 \mathrm{~cm}^{-1}$ are related to O-H and aliphatic C$\mathrm{H}$ stretching; the peaks from 1402 to $1680 \mathrm{~cm}^{-1}$ are corresponded to $\mathrm{C}=\mathrm{C}$ and $\mathrm{C}=\mathrm{O}$ stretching, and the peaks at 1199 and $1100 \mathrm{~cm}^{-1}$ could be ascribed to -C-O and C-O-C stretching. The formation of FeNPs is approved by the presence of the peaks at wavenumbers of 451,529 , and $614 \mathrm{~cm}^{-1}$. These peaks attribute to bending vibration of Fe-O. Similar peaks with some differences in the wavenumber have been reported for green-synthetic FeNPs by other research groups [20-22]. 


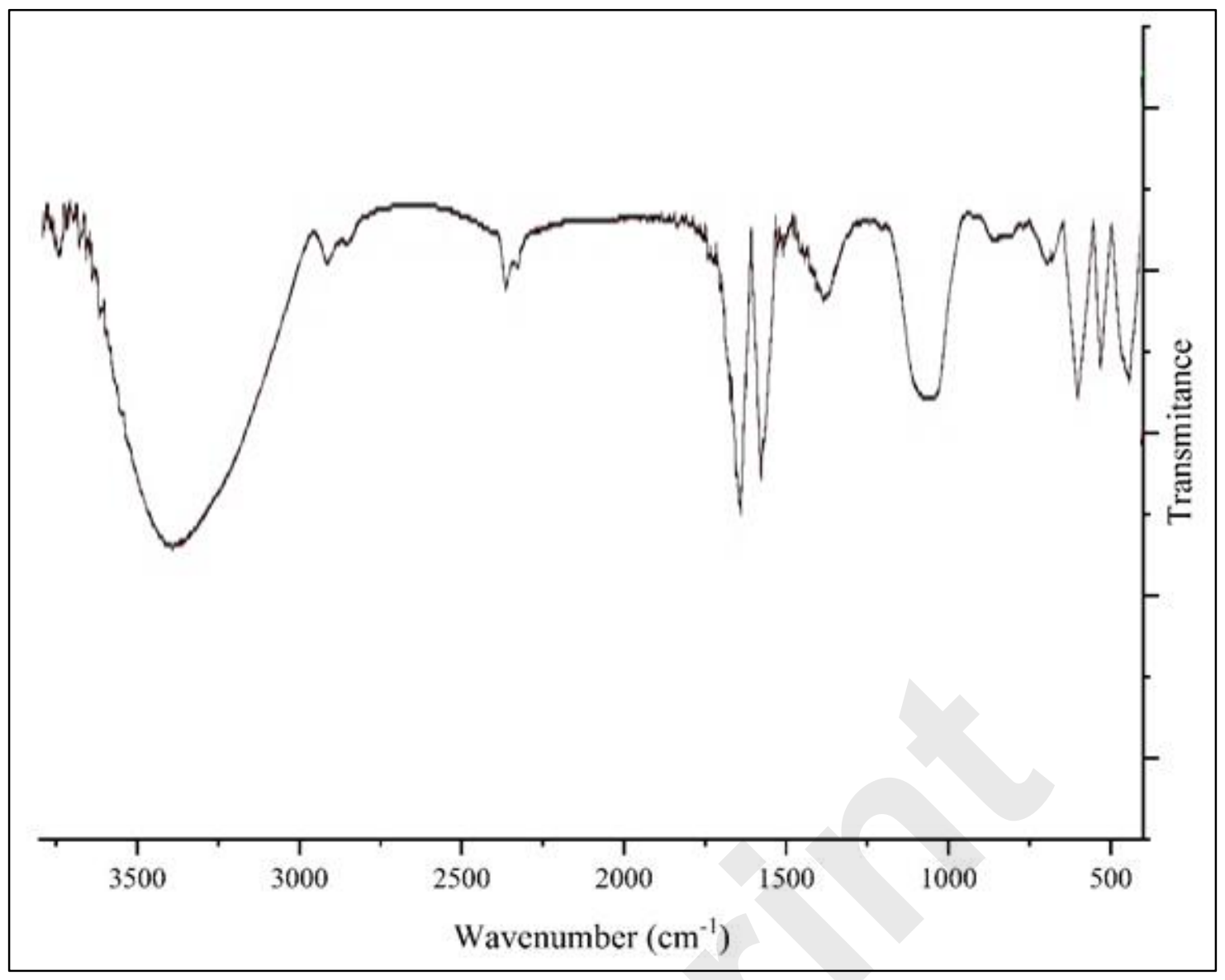

Figure 2: FT-IR spectra of biosynthesized FeNPs

SEM analysis: The SEM device is one of the most powerful tools used in various fields, including nanotechnology, which uses electron bombardment to produce images of objects as small as 10 nanometers. The bombardment of the sample causes positively charged electrons to be released from the sample to the plate, where these electrons become signals [23-29].

The morphology of FeNPs was assessed by the SEM technique. Figure 3 presents the SEM of FeNPs. The images show the spherical shape for the nanoparticles with average particle size of $47.24 \mathrm{~nm}$. Furthermore, the nanoparticles are aggregated. In our literature review, 8.36 to $86.12 \mathrm{~nm}$ was reported for biosynthesized of iron oxide using plant extracts as the capping agent [23-29]. 


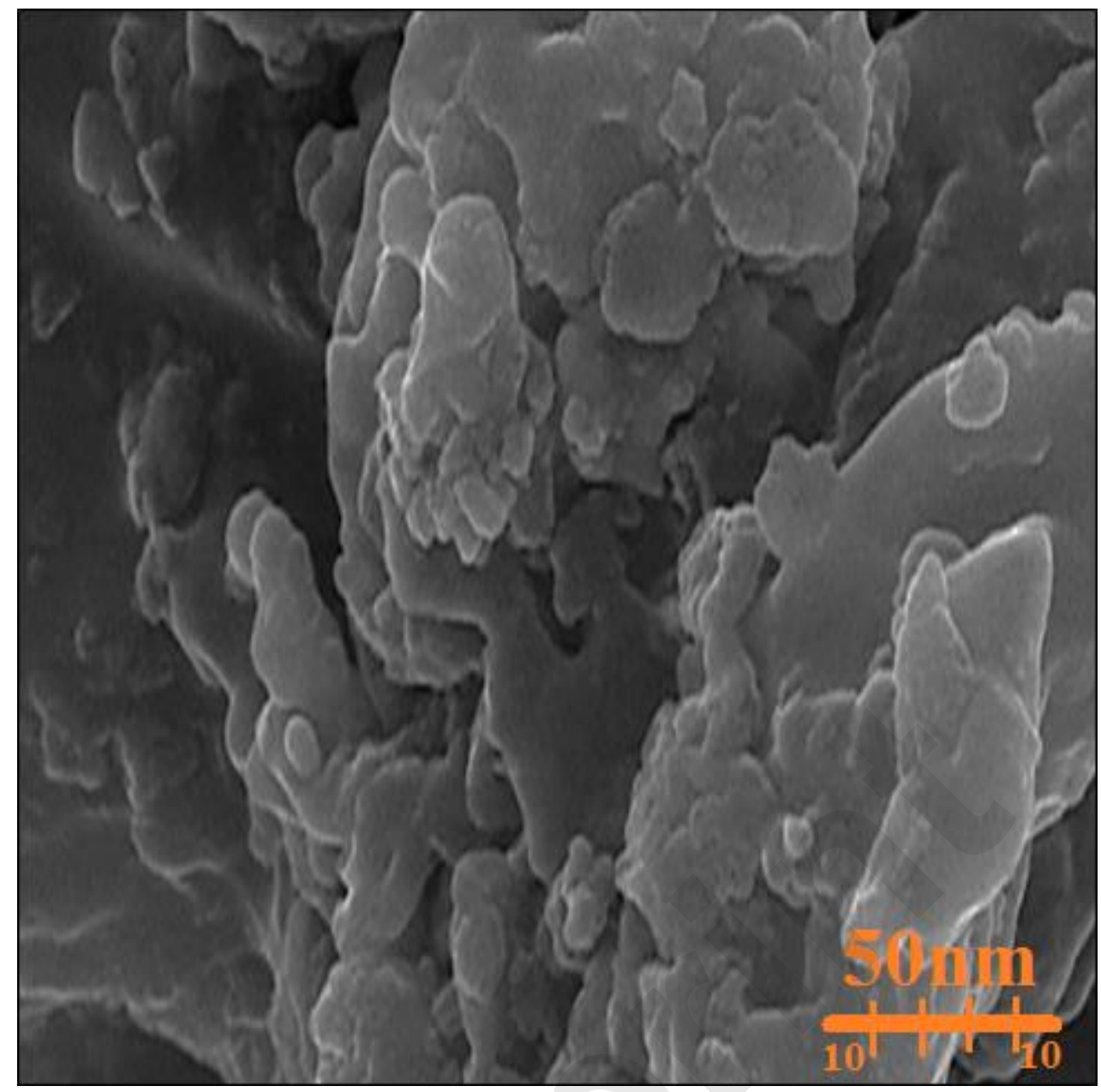

Figure 3. SEM Images of FeNPs

TEM analysis. TEM (transmission electron microscope) is used for determining the structure and morphology of materials. TEM transmission electron microscope products enable microstructural studies with high resolution and high magnification such as studies of crystal structures, symmetry, orientation and crystal defects. TEM and SEM microscopes differ in how the beam passes and the information obtained from the sample. Scanning microscopes take pictures of the sample surface, while passing microscopes take pictures of the inside of the sample. The resolution and magnification of electron microscopes are higher than those of scanning electron microscopes. The electron beams in the scanning electron microscope scan the surface of the sample point-bypoint, but the TEM microscope beams hit and pass through the entire sample. In addition, sample preparation for the SEM microscope is easier than for the TEM microscope [23-30].

TEM is the other test for determining the morphology and size of metallic nanoparticles. In our study, the range size of the nanoparticles (11-62 nm) calculated through TEM images (Figure 4). Furthermore, the histogram plot from the TEM image showed the particle size distribution of biosynthesized iron nanoparticles ranges of 10 to 54 $\mathrm{nm}$. In the previous studies, the size of iron nanoparticles formulated by aqueous extract of medicinal plants had been calculated in the ranges of 5-100 nm with the shape of spherical [23-30]. These reports support the results of the current work. 


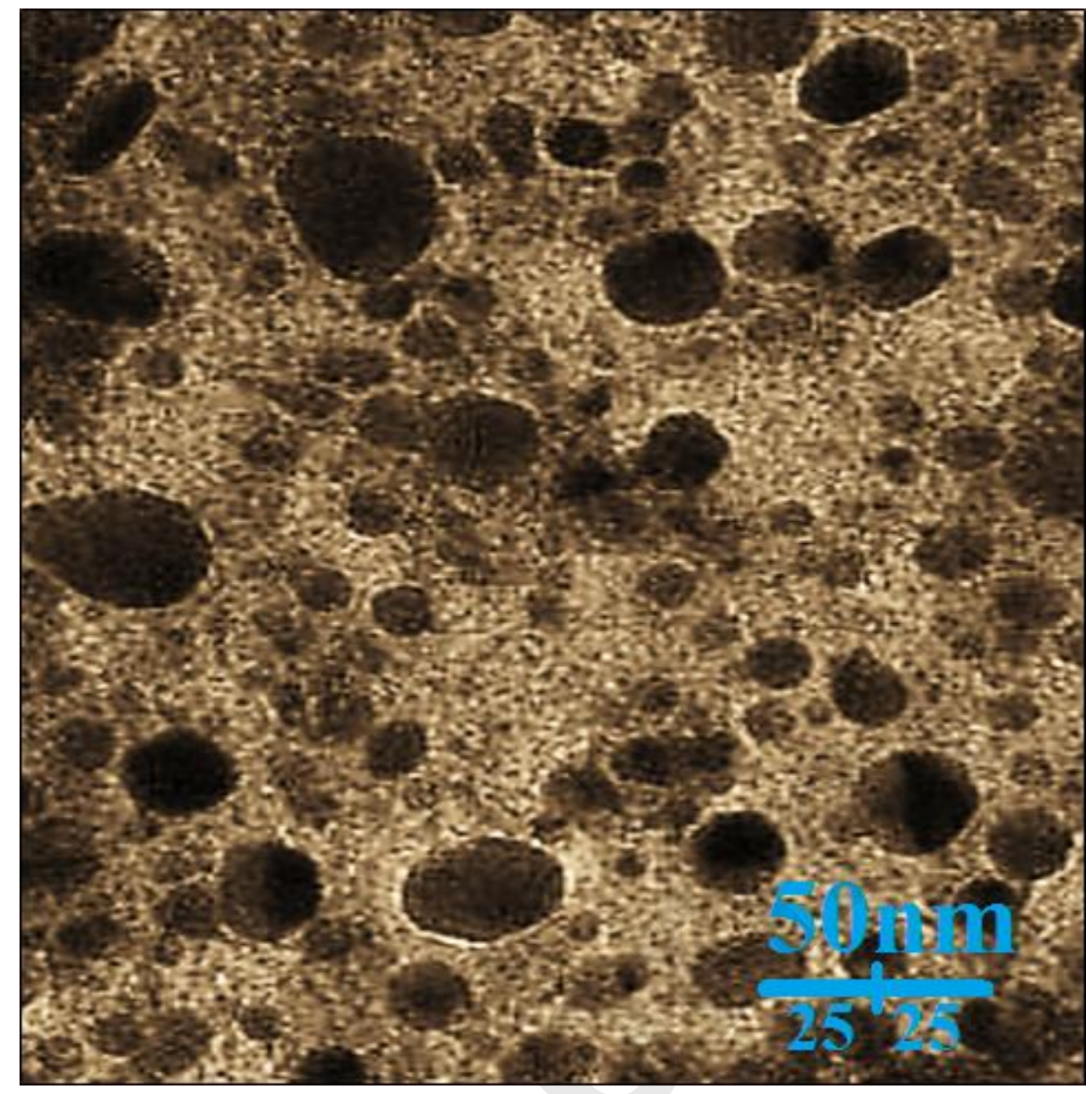

Figure 4. TEM Images of FeNPs

\subsection{Cytotoxicity, anti-human colorectal carcinoma, and antioxidant activities of FeNPS}

The gradual maturation of nanotechnology has been considered not only for treating cancer but also for a wide variety of applications, especially for drug delivery and diagnostic and imaging cases. There are many types of nanoparticles available and choosing the right carriers according to demand is a key issue [32-35]. Nanoparticles are very close in size to biological molecules in terms of size and can easily penetrate into the cell, for this reason, one of the goals of nanotechnology is to mount molecules and drugs on nanoparticles and transfer them to the target cell [31-35]. It is also possible to create different surface properties for nanoparticles by attaching protective ligands to increase the nanoparticles' resistance to the immune system and increase their presence in the bloodstream, and even binding ligands to specifically bind the nanoparticles to the target tissue [32-36].

In this research, the treated cells with different concentrations of the present FeNPs were assessed by MTT assay for $48 \mathrm{~h}$ about the cytotoxicity properties on normal (HUVEC) and colorectal malignancy cell lines i.e., HT-29, HCT 116, HCT-8, and Ramos.2G6.4C10. 
The absorbance rate was evaluated at $570 \mathrm{~nm}$, which represented viability on normal cell line (HUVEC) even up to $1000 \mu \mathrm{g} / \mathrm{mL}$ for FeNPs (Tables 1 and Figure 5).

The viability of malignant colorectal cell line reduced dose-dependently in the presence of FeNPs. The IC50 of FeNPs were 250, 293, 276, and $344 \mu \mathrm{g} / \mathrm{mL}$ against HT-29, HCT 116, HCT-8, and Ramos.2G6.4C10 cell lines, respectively. The IC50 of Alhagi sparsifolia were 580, 519, 582, and $528 \mu \mathrm{g} / \mathrm{mL}$ against HT-29, HCT 116, HCT8, and Ramos.2G6.4C10 cell lines, respectively (Tables 1 and Figure 5-9).

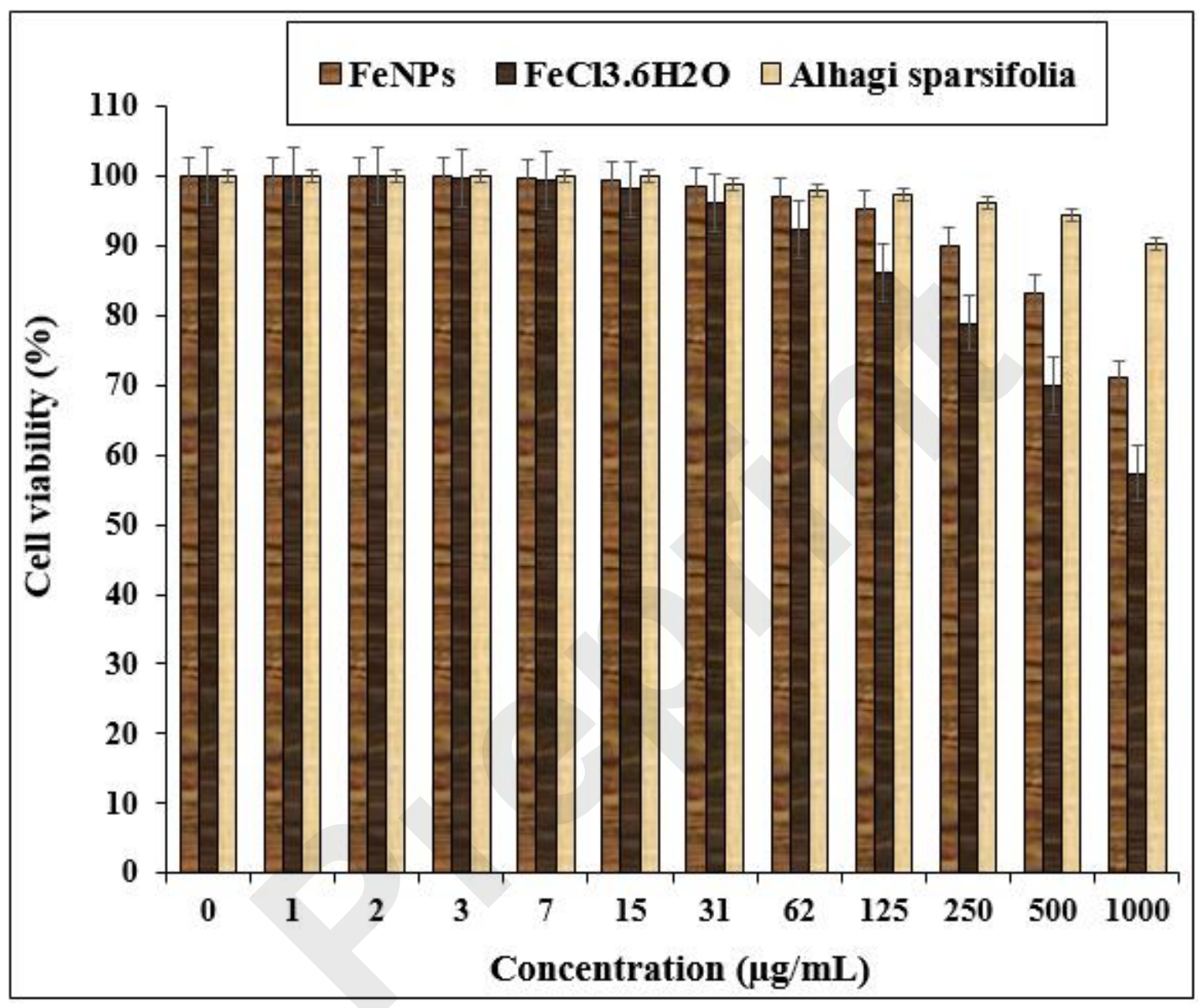

FIGURE 5 The cytotoxicity properties of $\mathrm{FeCl}_{3} .6 \mathrm{H}_{2} \mathrm{O}$, Alhagi sparsifolia and FeNPs against HUVEC cell line. 


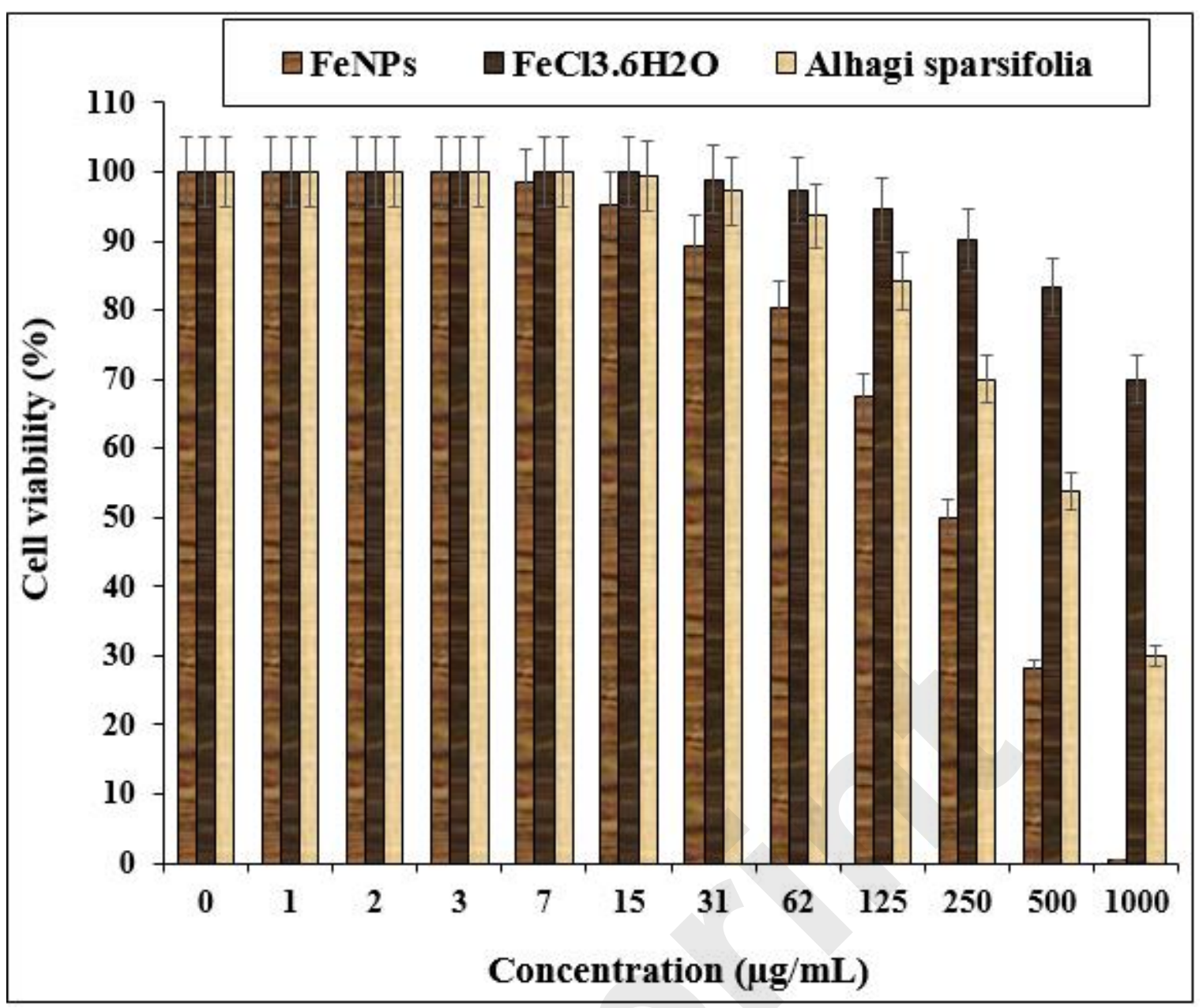

FIGURE 6. The anti-human colorectal carcinoma properties of $\mathrm{FeCl}_{3} \cdot 6 \mathrm{H}_{2} \mathrm{O}$, Alhagi sparsifolia and FeNPs against HT-29 cell line. 


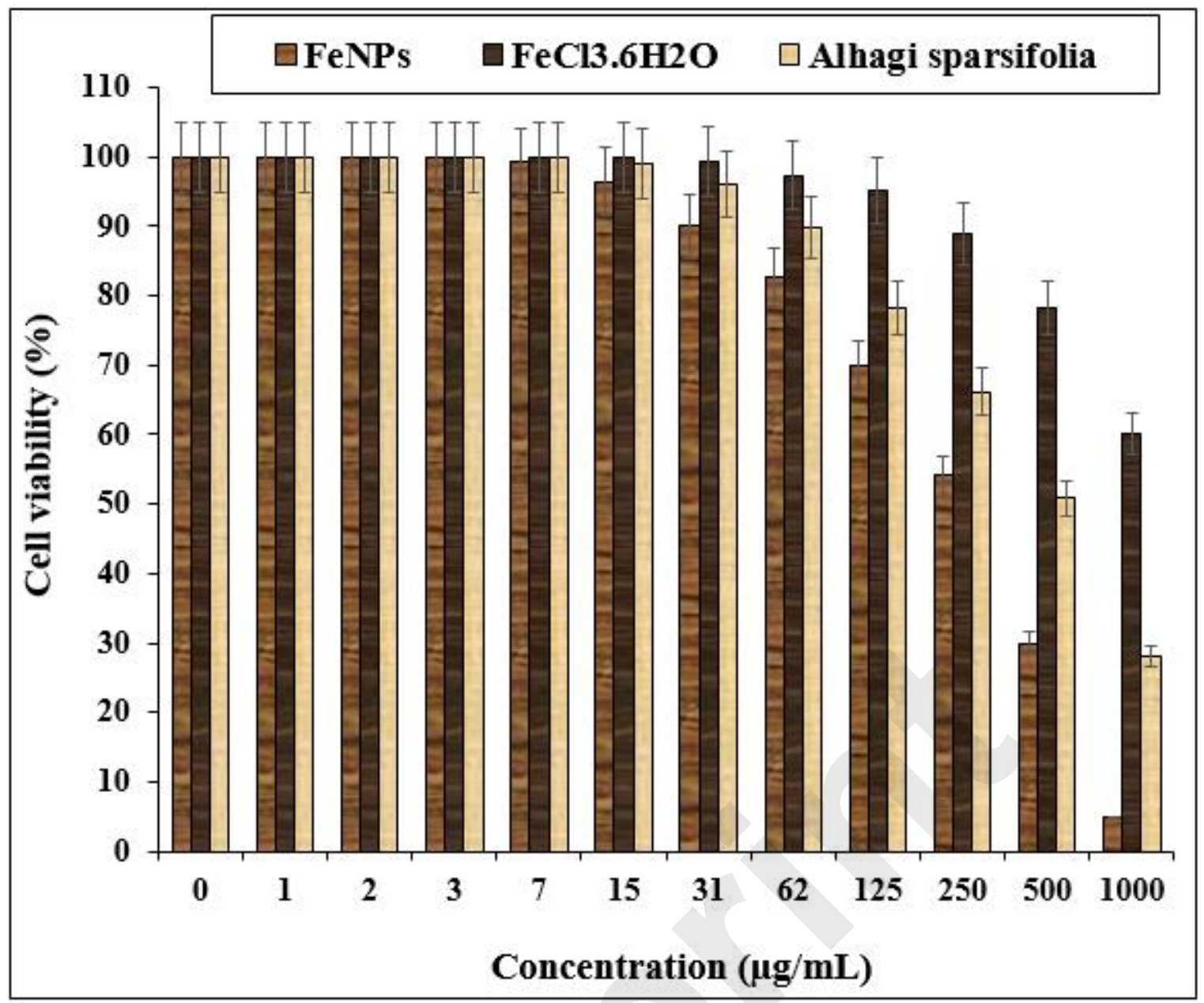

FIGURE 7. The anti-human colorectal carcinoma properties of $\mathrm{FeCl}_{3} \cdot 6 \mathrm{H}_{2} \mathrm{O}$, Alhagi sparsifolia and FeNPs against HCT 116 cell line. 


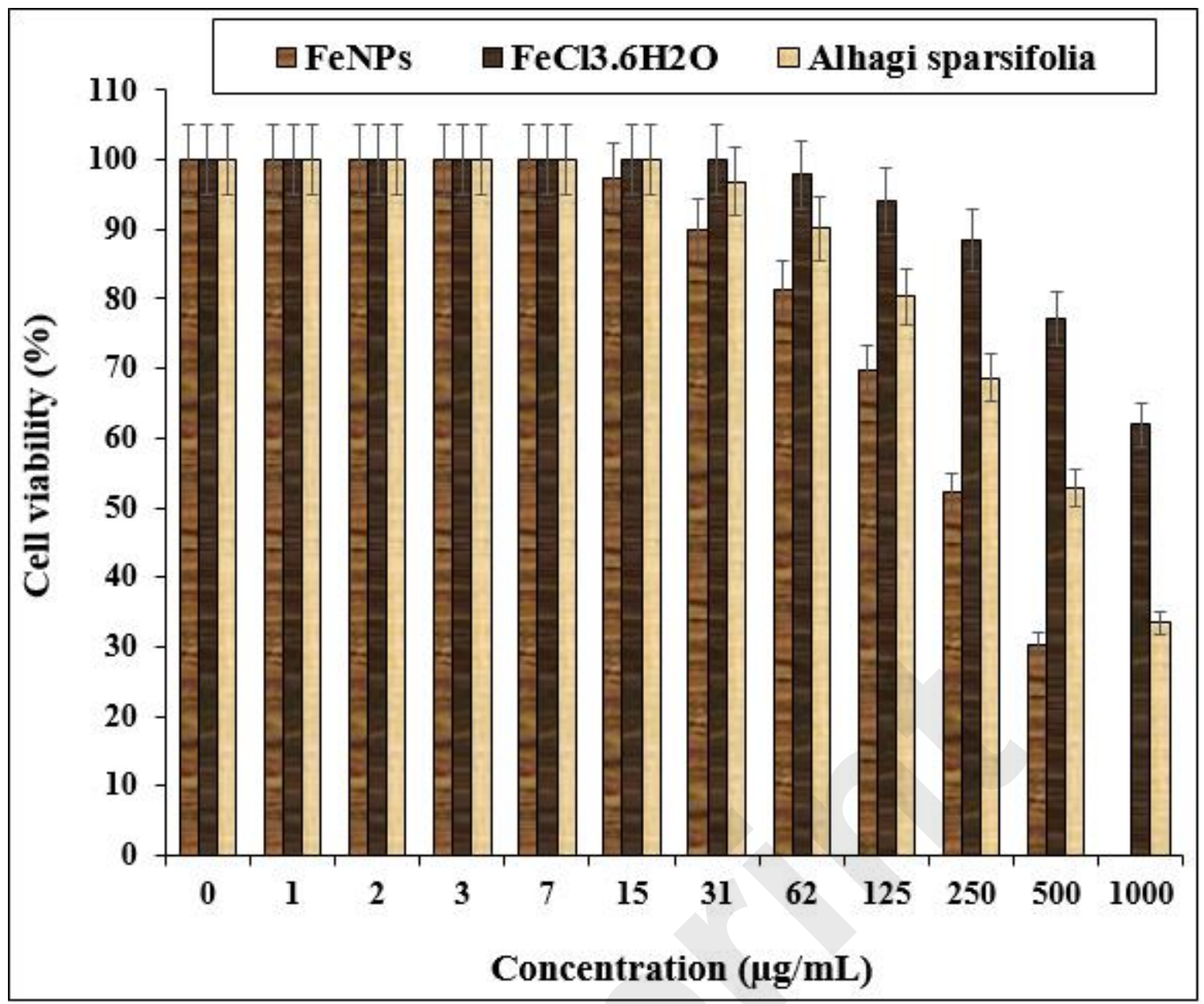

FIGURE 8. The anti-human colorectal carcinoma properties of $\mathrm{FeCl}_{3} \cdot 6 \mathrm{H}_{2} \mathrm{O}$, Alhagi sparsifolia and FeNPs against HCT-8 cell line. 


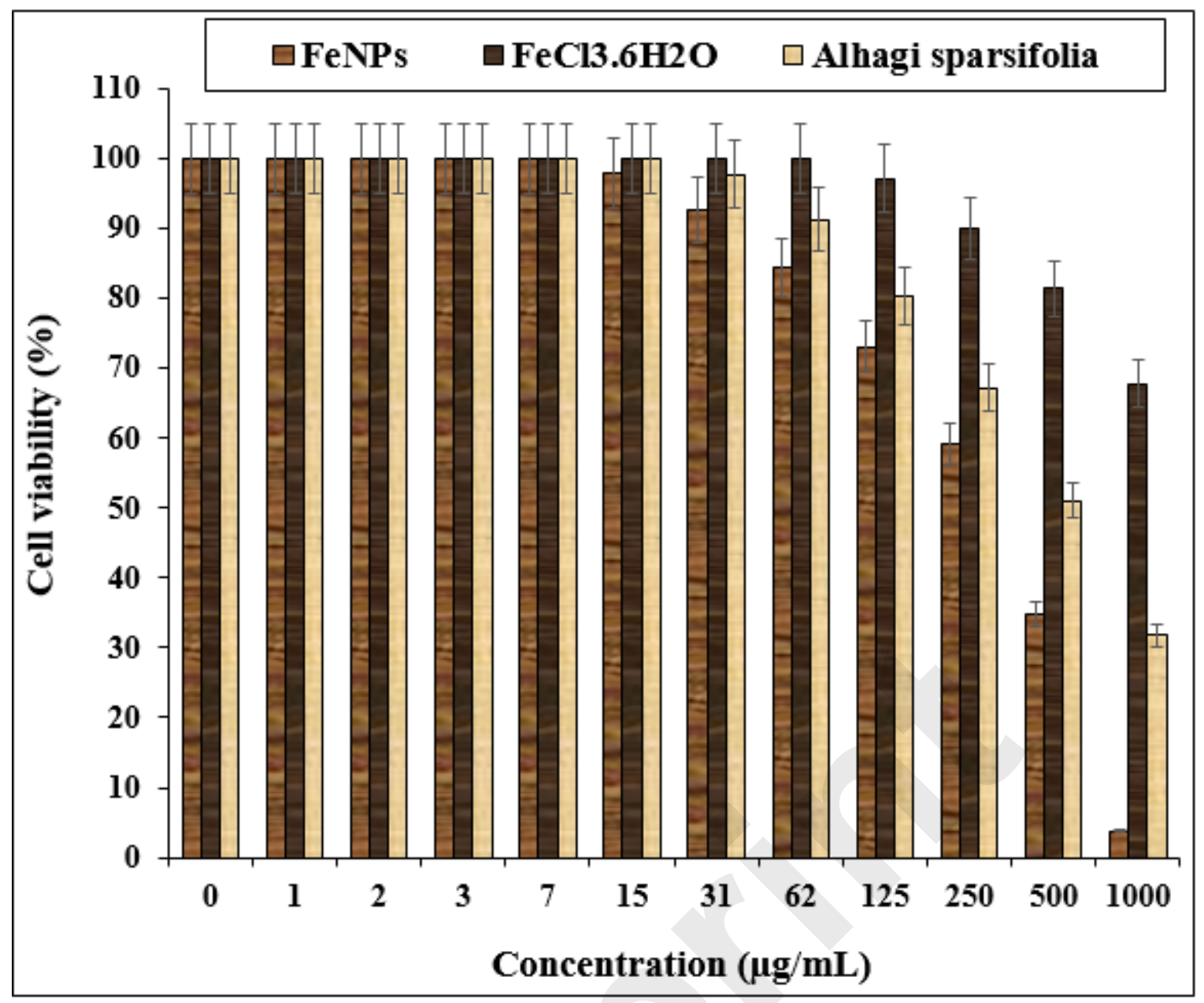

FIGURE 9. The anti-human colorectal carcinoma properties of $\mathrm{FeCl}_{3} \cdot 6 \mathrm{H}_{2} \mathrm{O}$, Alhagi sparsifolia and $\mathrm{FeNPs}$ against Ramos.2G6.4C10 cell line.

TABLE 1 The IC50 of $\mathrm{FeCl}_{3} .6 \mathrm{H}_{2} \mathrm{O}$, Alhagi sparsifolia and FeNPs in cytotoxicity test.

\begin{tabular}{|c|c|c|c|}
\hline & FeCl3.6H2O $(\boldsymbol{\mu g} / \mathbf{m L})$ & $\begin{array}{c}\text { Alhagi sparsifolia } \\
(\boldsymbol{\mu g} / \mathbf{m L})\end{array}$ & FeNPs $(\boldsymbol{\mu g} / \mathbf{m L})$ \\
\hline IC50 against HUVEC & - & - & - \\
\hline IC50 against HT-29 & - & $580 \pm 0^{\mathrm{c}}$ & $250 \pm 0^{\mathrm{a}}$ \\
\hline IC50 against HCT 116 & - & $519 \pm 0^{\mathrm{c}}$ & $293 \pm 0^{\mathrm{ab}}$ \\
\hline IC50 against HCT-8 & - & $582 \pm 0^{\mathrm{c}}$ & $276 \pm 0^{\mathrm{a}}$ \\
\hline $\begin{array}{c}\text { IC50 against } \\
\text { Ramos.2G6.4C10 }\end{array}$ & - & $528 \pm 0^{\mathrm{c}}$ & $344 \pm 0^{\mathrm{b}}$ \\
\hline
\end{tabular}

The different words indicate the significant differences between several groups.

It seems that the anti-human colorectal carcinoma effect of recent nanoparticles is due to their antioxidant effects. Because tumor progression is so closely linked to inflammation and oxidative stress, a compound with antiinflammatory or antioxidant properties can be an anticarcinogenic agent [22,23]. Many nanoparticles have 
pharmacological and biochemical properties, including antioxidant and anti-inflammatory properties, which appear to be involved in anticarcinogenic and antimutagenic activities [22-24].

In this study, we assessed the antioxidant properties of Alhagi sparsifolia leaf aqueous extract green-synthesized FeNPs by using the DPPH test as a common free radical. Oxidation is the electrons transfer from an atom and is the aerobic life and metabolism part of living organisms. Oxygen is the receptor for electrons in the electron transport system, which yields energy from ATP (Adenosine triphosphate) in the body. Under certain conditions, oxygen may become a single electron and release free radicals. When oxygen becomes a single electron, it is called reactive oxygen species (ROS). Oxidative loss to proteins, DNA, and other macromolecules is one of the internal causes of degenerative diseases such as aging, cardiovascular disease, cancer, immune system deficiency, cataracts, and abnormal brain function. Single oxygen, high-energy, mutagenic oxygen, can be produced by lipid peroxidation by the transmission of energy from light or the respiratory tract of neutrophils $[10,11,12]$. Some free radicals have positive roles such as regulating cell growth, phagocytosis, energy production, intracellular signals, or the important biological compounds synthesis. Antioxidants produced in the body fight free radicals with two systems: enzymatic defense and non-enzymatic defense. Superoxide dismutase, catalase, and glutathione peroxidase metabolize lipid peroxide, hydrogen peroxide, and superoxide and prevent the production of toxic hydroxyl radicals $[12,15]$. In non-enzymatic defense, there are two classes of fat-soluble antioxidants (such as carotenoids and vitamin E) and water-soluble (glutathione and vitamin C) that trap free radicals. These two systems help neutralize oxidants. However, oxidants can escape from antioxidants and damage tissues. In this case, the activated antioxidant repair system (which is the enzymes lipase, protease, transferase and DNA repair enzymes), counteract the oxidant effects. However, due to deficiencies in the production of antioxidants in the body or due to physiopathological factors and situations (such as smoking, air pollution, UV radiation, diets containing high unsaturated fatty acids, inflammation, ischemia, bleeding, etc) that ROS are yielded in large quantities at the wrong place and time, oral antioxidants are needed to counteract the oxidative damage cumulative effects $[11,12,15]$.

The scavenging capacity of Alhagi sparsifolia leaf aqueous extract green-synthesized FeNPs and BHT at different concentrations expressed as percentage inhibition has been indicated in Tables 2 and Figure 10.

In the antioxidant test, the IC50 of FeNPs and BHT against DPPH free radicals were 161 and $134 \mu \mathrm{g} / \mathrm{mL}$, respectively (Tables 2 and Figure 10). 


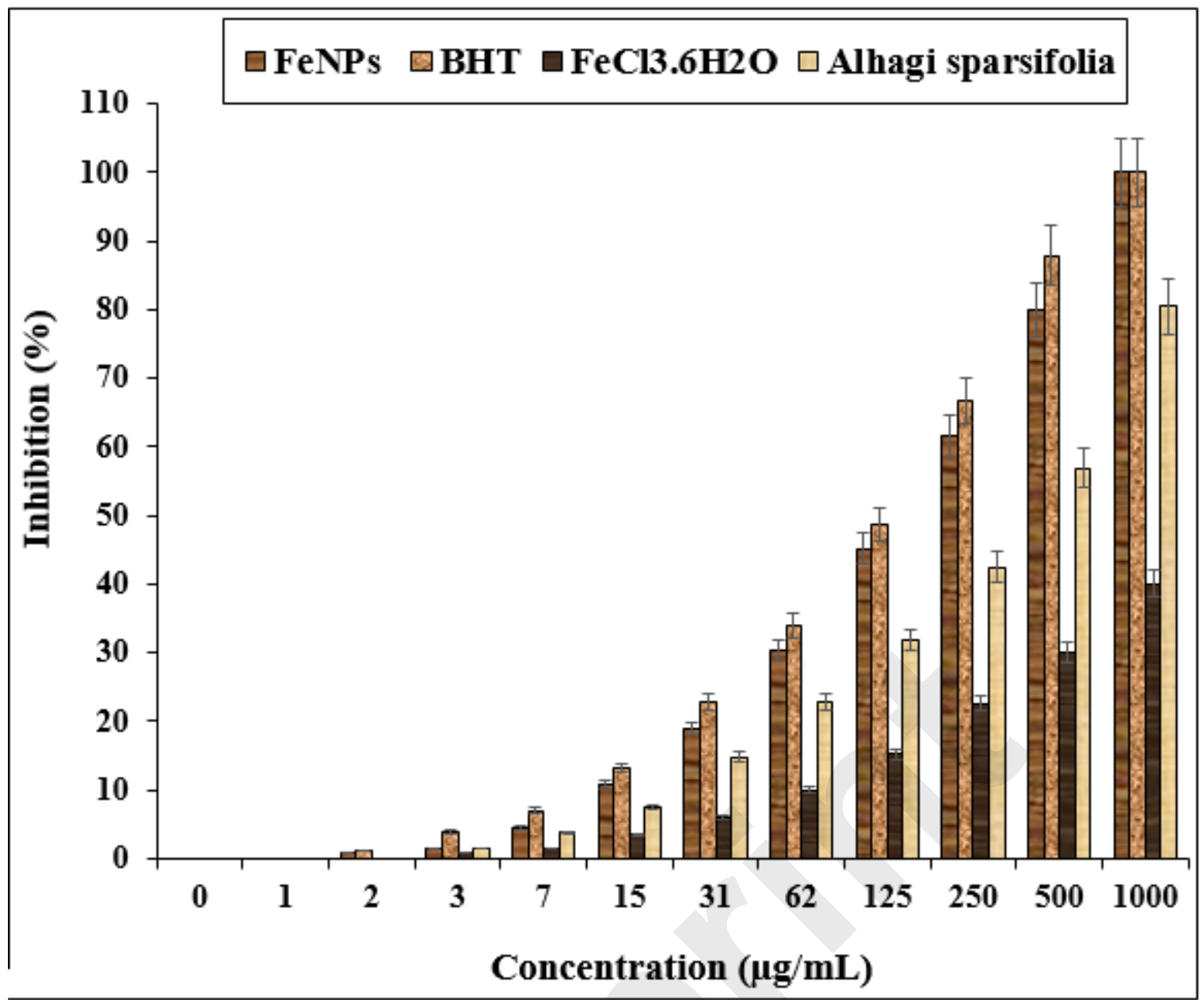

FIGURE 10. The antioxidant properties of $\mathrm{FeCl}_{3} .6 \mathrm{H}_{2} \mathrm{O}$, Alhagi sparsifolia, FeNPs and BHT against DPPH.

TABLE 2 The IC50 of $\mathrm{FeCl}_{3} \cdot 6 \mathrm{H}_{2} \mathrm{O}$, Alhagi sparsifolia, FeNPs and BHT in antioxidant test.

\begin{tabular}{|l|c|c|c|c|}
\hline & $\begin{array}{c}\text { FeCl3.6H2O } \\
(\boldsymbol{\mu g} / \mathbf{m L})\end{array}$ & $\begin{array}{c}\text { Alhagi sparsifolia } \\
(\boldsymbol{\mu g} / \mathbf{m L})\end{array}$ & FeNPs $(\boldsymbol{\mu g} / \mathbf{m L})$ & BHT $(\boldsymbol{\mu g} / \mathbf{m L})$ \\
\hline IC50 against DPPH & - & $380 \pm 0^{\mathrm{b}}$ & $161 \pm 0^{\mathrm{a}}$ & $134 \pm 0^{\mathrm{a}}$ \\
\hline
\end{tabular}

The different words indicate the significant differences between several groups.

\section{Conclusion}

Cancer can be treated in several ways: surgery, chemotherapy, radiation therapy, immunotherapy, gene therapy, or a combination of these. Due to the relative inefficiency and very severe side effects of chemotherapy drugs, researchers and scientists have sought a new formulation of various compounds, especially metallic nanoparticles. In summary, the green synthesis of iron nanoparticles was carried out using an aqueous extract of Alhagi 
sparsifolia. The nanoparticles were characterized using common chemical techniques such as UV-Visible, FTIR, SEM, and TEM. The SEM images indicated a spherical morphology for FeNPs with average size of 47.24 $\mathrm{nm}$, which is well known as a sufficient size for the synthetic nanoparticles. The FeNPs showed the best antioxidant activities against DPPH. The IC50 of FeNPs and BHT against DPPH free radicals were 161 and 134 $\mu \mathrm{g} / \mathrm{mL}$, respectively. The viability of malignant colorectal cell line reduced dose-dependently in the presence of FeNPs. The IC50 of FeNPs were 250, 293, 276, and $344 \mu \mathrm{g} / \mathrm{mL}$ against HT-29, HCT 116, HCT-8, and Ramos.2G6.4C10 cell lines, respectively. After clinical study, FeNPs containing Alhagi sparsifolia leaf aqueous extract can be utilized as an efficient drug in the treatment of colorectal carcinoma in humans.

\section{Acknowledgement:}

This project was supported by Researchers Supporting Project number (RSP-2021/230) King Saud University, Riyadh, Saudi Arabia.

\section{References}

[1] A. Al-Snai, M.L. Al-Kamel, M.E. Esmael, Antifungal effect of Alhagi maurorum phenolic extract, IOSR Journal of Pharmacy, 9 (2019) 7-14.

[2] A.H. Laghari, S. Memon, A. Nelofar, K.M. Khan, Alhagi maurorum: A convenient source of lupeol, Industrial Crops and Products, 34 (2011) 1141-1145.

[3] A. Awaad Amani, D. Maitland, G. Soliman, Antiulcerogenic activity of Alhagi maurorum, Pharmaceutical biology, 44 (2006) 292-296.

[4] A.H. Laghari, A. Ali Memon, S. Memon, A. Nelofar, K.M. Khan, A. Yasmin, Determination of free phenolic acids and antioxidant capacity of methanolic extracts obtained from leaves and flowers of camel thorn (Alhagi maurorum), Natural product research, 26 (2012) 173-176.

[5] A. Hamed, A. Perrone, U. Mahalel, W. Oleszek, A. Stochmal, S. Piacente, Oleanane glycosides from the roots of Alhagi maurorum, Phytochemistry Letters, 5 (2012) 782-787.

[6] N. Ahmad, Z.K. Shinwari, J. Hussain, R. Perveen, Phytochemicals, antibacterial and antioxidative investigations of Alhagi maurorum medik, Pakistan Journal of Botany, 47 (2015) 121-124.

[7] B. Olas, A.I. Hamed, W. Oleszek, A. Stochmal, Comparison of biological activity of phenolic fraction from roots of Alhagi maurorum with properties of commercial phenolic extracts and resveratrol, Platelets, 26 (2015) 788-794. 
[8] S. Akbar, Handbook of 200 medicinal plants: A comprehensive review of their traditional medical uses and scientific justifications, DOI (2020).

[9] M.S.M. Al-Saleem, L.H. Al-Wahaib, W.M. Abdel-Mageed, Y.G. Gouda, H.M. Sayed, Antioxidant flavonoids from Alhagi maurorum with hepatoprotective effect, Pharmacognosy Magazine, 15 (2019) 592.

[10] (a) Ghashghaii, A., Hashemnia, M., Nikousefat, Z., Zangeneh, M.M., Zangeneh, A., 2017. Pharmaceutical Sciences 23, 256-263. (b) Goorani, S., Shariatifar, N., Seydi, N., Zangeneh, A., Moradi, R., Tari, B., Nazari, F., Zangeneh, M.M., 2019. Oriental Pharmacy and Experimental Medicine 19, 403-413.

[11] (a) Abdoli, M., Sadrjavadi, K., Arkan, E., Zangeneh, M.M., Moradi, S., Zangeneh, A., Shahlaei, M., Khaledian S. 2020. J Drug Deliv Sci Technol. 60, 102044. (b) Dou, L., Zhang, X., Zangeneh, M.M., Zhang, Y. 2020. Bioorg. Chem. 106: 104468. (c) Han, Y., Gao, Y., Cao, X., Zangeneh, M.M., Liu, S., Li, J. 2020. Int. J. Biol. Macromol. 164: 2974-2986.

[12] (a) Sujayev, A., Taslimi, P., Garibov, E., Karaman, M., Zangeneh, M.M., 2020. Bioorg. Chem. 104: 104216. (b) Sun, T., Gao, J., Shi, H., Han, D., Zangeneh, M.M., Liu, N., Liu, H., Guo, Y., Liu. X., 2020. Int. J. Biol. Macromol. 165: 787-795.

[13] Kooti W, Servatyari K, Behzadifar M, et al. Effective Medicinal Plant in Cancer Treatment, Part 2: Review Study. J Evid Based Complementary Altern Med. 2017;22(4):982-995. doi:10.1177/2156587217696927.

[14] W. S. Hummers, R. E. Offeman. J. Am. Chem. Soc. 80 (1958) 1339-1339.

[15] A. Soni, R. Krishnamurthy, Indian J Plant Sci. 2013, 2, 117-125.

[16] Y. Wei, Z. Fang, L. Zheng, L. Tan, E.P. Tsang, Green synthesis of Fe nanoparticles using Citrus maxima peels aqueous extracts, Materials Letters, 185 (2016) 384-386.

[17] Arunachalam KD et al. One-step green synthesis and characterization of leaf extract-mediated biocompatible silver and gold nanoparticles from Memecylon umbellatum. Int J Nanomedicine. 2003; 8: 13071315.

[18] L. Katata-Seru, T. Moremedi, O.S. Aremu, I. Bahadur, Green synthesis of iron nanoparticles using Moringa oleifera extracts and their applications: Removal of nitrate from water and antibacterial activity against Escherichia coli, Journal of Molecular Liquids, 256 (2018) 296-304.

[19] M. Harshiny, C.N. Iswarya, M. Matheswaran, Biogenic synthesis of iron nanoparticles using Amaranthus dubius leaf extract as a reducing agent, Powder technology, 286 (2015) 744-749.

[20] I.A. Radini, N. Hasan, M.A. Malik, Z. Khan, Biosynthesis of iron nanoparticles using Trigonella foenumgraecum seed extract for photocatalytic methyl orange dye degradation and antibacterial applications, Journal of Photochemistry and Photobiology B: Biology, 183 (2018) 154-163. 
[21] N. Beheshtkhoo, M.A.J. Kouhbanani, A. Savardashtaki, A.M. Amani, S. Taghizadeh, Green synthesis of iron oxide nanoparticles by aqueous leaf extract of Daphne mezereum as a novel dye removing material, Applied Physics A, 124 (2018) 363-369.

[22] S. Sangami, B. Manu, Synthesis of Green Iron Nanoparticles using Laterite and their application as a Fenton-like catalyst for the degradation of herbicide Ametryn in water, Environmental Technology \& Innovation, 8 (2017) 150-163.

[23] C. Devatha, K. Jagadeesh, M. Patil, Effect of green synthesized iron nanoparticles by Azardirachta indica in different proportions on antibacterial activity, Environmental Nanotechnology, Monitoring \& Management, 9 (2018) 85-94.

[24] S. Zhang, D. Wu, H. Li, J. Zhu, W. Hu, M. Lu, X. Liu, Rapid identification of $\alpha$-glucosidase inhibitors from Dioscorea opposita Thunb peel extract by enzyme functionalized $\mathrm{Fe}_{3} \mathrm{O}_{4}$ magnetic nanoparticles coupled with HPLC-MS/MS, Food \& function, 8 (2017) 3219-3227.

[25] A. Gautam, S. Rawat, L. Verma, J. Singh, S. Sikarwar, B. Yadav, A.S. Kalamdhad, Green synthesis of iron nanoparticle from extract of waste tea: An application for phenol red removal from aqueous solution, Environmental nanotechnology, monitoring \& management, 10 (2018) 377-387.

[26] J.K. Patra, K.-H. Baek, Green biosynthesis of magnetic iron oxide $\left(\mathrm{Fe}_{3} \mathrm{O}_{4}\right)$ nanoparticles using the aqueous extracts of food processing wastes under photo-catalyzed condition and investigation of their antimicrobial and antioxidant activity, Journal of Photochemistry and Photobiology B: Biology, 173 (2017) 291-300.

[27] M. Nurbas, H. Ghorbanpoor, H. Avci, An Eco-Friendly Approach to Synthesis and Charactrization of Magnetite $\left(\mathrm{Fe}_{3} \mathrm{O}_{4}\right)$ Nanoparticles Using Platanus orientalis L. Leaf Extract, Digest Journal of Nanomaterials \& Biostructures (DJNB), 12 (2017) 993-1000.

[28] Y.P. Yew, K. Shameli, M. Miyake, N. Kuwano, N.B.B.A. Khairudin, S.E.B. Mohamad, K.X. Lee, Green synthesis of magnetite $\left(\mathrm{Fe}_{3} \mathrm{O}_{4}\right)$ nanoparticles using seaweed (Kappaphycus alvarezii) extract, Nanoscale research letters, 11 (2016) 276-282.

[29] Y. Kuang, Q. Wang, Z. Chen, M. Megharaj, R. Naidu, Heterogeneous Fenton-like oxidation of monochlorobenzene using green synthesis of iron nanoparticles, Journal of colloid and interface science, 410 (2013) 67-73.

[30] Y. Kuang, Q. Wang, Z. Chen, M. Megharaj, R. Naidu, Heterogeneous Fenton-like oxidation of monochlorobenzene using green synthesis of iron nanoparticles, Journal of colloid and interface science, 410 (2013) 67-73. 
[13] (a) Veisi, H.; Tamoradi, T.; Karmakar, B. Mohammadi, P.; Hemmati, S.; Mat. Sci. Eng. C. 104 (2019) 109919; (b) M. Hamelian, K. Varmira, H. Veisi, ournal of Photochemistry and Photobiology B: Biology 184 (2018) 71-79.

[31] Katata-Seru L, Moremedi T, Aremu OS, et al. Green synthesis of iron nanoparticles using Moringa oleifera extracts and their applications: Removal of nitrate from water and antibacterial activity against Escherichia coli. J Mol Liq 2018; 256: 296-304.

[32] Sankar R, Maheswari R, Karthik S, et al. Anticancer activity of Ficus religiosa engineered copper oxide nanoparticles. Mat Sci Eng C 2014; 44: 234-239.

[33] Tahvilian R, Zangeneh MM, Falahi H, et al. Green synthesis and chemical characterization of copper nanoparticles using Allium saralicum leaves and assessment of their cytotoxicity, antioxidant, antimicrobial, and cutaneous wound healing properties. Appl Organometal Chem. 2019; 33: e5234. DOI: 10.1002/aoc.5234.

[34] Mao BH et al. Mechanisms of silver nanoparticle-induced toxicity and important role of autophagy. Nanotoxicol. 2016; 10: 1021-1040.

[35] You C, Han C, Wang X, et al. The progress of silver nanoparticles in the antibacterial mechanism, clinical application and cytotoxicity, Mol. Biol. Rep. 2012; 39: 9193-9201. https://doi.org/10.1007/s11033-012-1792-8.

[36] Namvar F, Rahman HS, Mohamad R, et al. Cytotoxic effect of magnetic iron oxide nanoparticles synthesized via seaweed aqueous extract. Int J Nanomedicine 2014; 19: 2479-88. 